\title{
Detection of gelatinolytic activity in developing basement membranes of the mouse embryo head by combining sensitive in situ zymography with immunolabeling
}

\author{
Nikolaos Gkantidis - Christos Katsaros • \\ Matthias Chiquet
}

Accepted: 29 May 2012/Published online: 12 June 2012

(C) Springer-Verlag 2012

\begin{abstract}
Genetic evidence indicates that the major gelatinases MMP-2 and MMP-9 are involved in mammalian craniofacial development. Since these matrix metalloproteinases are secreted as proenzymes that require activation, their tissue distribution does not necessarily reflect the sites of enzymatic activity. Information regarding the spatial and temporal expression of gelatinolytic activity in the head of the mammalian embryo is sparse. Sensitive in situ zymography with dye-quenched gelatin (DQ-gelatin) has been introduced recently; gelatinolytic activity results in a local increase in fluorescence. Using frontal sections of wild-type mouse embryo heads from embryonic day $14.5-15.5$, we optimized and validated a simple doublelabeling in situ technique for combining DQ-gelatin zymography with immunofluorescence staining. MMP inhibitors were tested to confirm the specificity of the reaction in situ, and results were compared to standard SDS-gel zymography of tissue extracts. Double-labeling was used to show the spatial relationship in situ between gelatinolytic activity and immunostaining for gelatinases MMP-2 and MMP-9, collagenase 3 (MMP-13) and MT1MMP (MMP-14), a major activator of pro-gelatinases. Strong gelatinolytic activity, which partially overlapped with MMP proteins, was confirmed for Meckel's cartilage and developing mandibular bone. In addition, we combined in situ zymography with immunostaining for extracellular
\end{abstract}

Electronic supplementary material The online version of this article (doi:10.1007/s00418-012-0982-8) contains supplementary material, which is available to authorized users.

N. Gkantidis · C. Katsaros · M. Chiquet $(\bowtie)$

Department of Orthodontics and Dentofacial Orthopedics, University of Bern, Freiburgstrasse 7, 3010 Bern, Switzerland

e-mail: matthias.chiquet@zmk.unibe.ch matrix proteins that are potential gelatinase substrates. Interestingly, gelatinolytic activity colocalized precisely with laminin-positive basement membranes at specific sites around growing epithelia in the developing mouse head, such as the ducts of salivary glands or the epithelial fold between tongue and lower jaw region. Thus, this sensitive method allows to associate, with high spatial resolution, gelatinolytic activity with epithelial morphogenesis in the embryo.

Keywords Mouse embryo - Craniofacial development . Matrix metalloproteinase - Basement membrane - In situ zymography $\cdot$ Dye-quenched gelatin $\cdot$ Immunofluorescence

\section{Introduction}

Extracellular matrix (ECM) remodeling is required for a variety of physiological processes during development and regeneration (Mott and Werb 2004). An important part of ECM remodeling is accomplished by the family of matrix metalloproteinases (MMPs), which counts at least 25 extracellular or membrane-bound members. MMPs are produced as proenzymes and become active after cleavage of their propeptide. Their main characteristic is the utilization of a $\mathrm{Zn}^{2+}$ metal ion to polarize a water molecule and perform the hydrolysis reaction (Clark et al. 2010; Parks et al. 2004). For years it was believed that the role of MMPs in the organism was limited to ECM degradation. However, a large number of non-matrix substrates have been identified, such as cytokines, growth factors, and proenzymes, indicating a much broader role of these enzymes in tissue homeostasis and the regulation of physiological and pathological processes (Aiken and Khokha 2010; Butler and Overall 2009). 

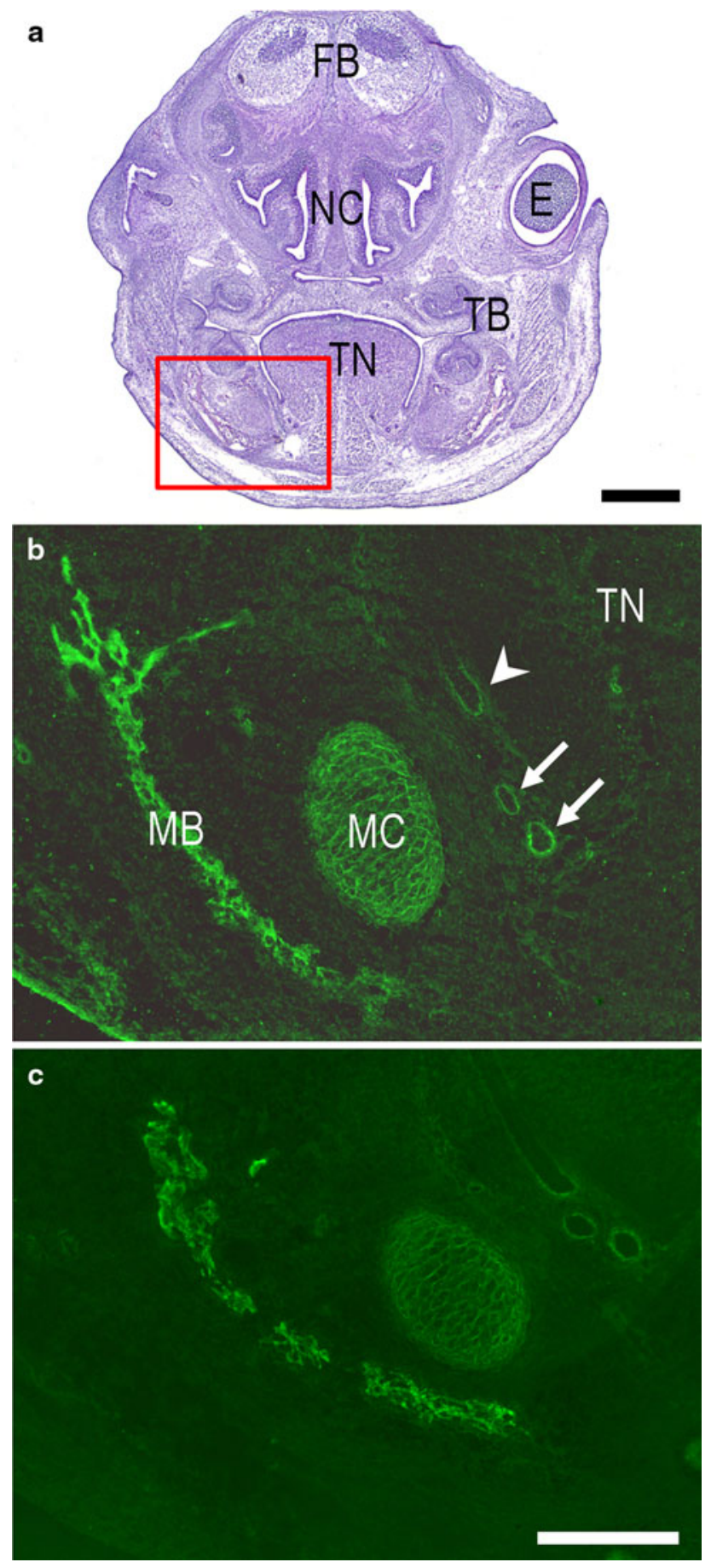

MMP-2 and MMP-9 are the major proteases with gelatinolytic activity in the organism. They are secreted proteins that can cleave a variety of ECM substrates but are particularly efficient in degrading partially denatured fibrillar collagens ("gelatin"). In addition, MMP-2 and -9 are involved in the degradation of native type IV collagen as well as laminin, major components of basement membranes (Odaka et al. 2005; Visse and Nagase 2003). Due to their role in basement membrane turnover, the gelatinases
Fig. 1 In situ zymography of craniofacial structures in the mouse embryo using dye-quenched (DQ)-gelatin. a Frontal section of a E14.5 wild-type mouse head stained with hematoxylin/eosin. The boxed area illustrates the region of interest that is presented in $\mathbf{b}$ and c, as well as in all following figures. b In situ zymography on an unfixed cryosection of the region of interest, performed by adding DQ-gelatin directly to the gelatinase reaction buffer (see "Materials and methods"). Prominent gelatinolytic activity, as manifested by increased fluorescence, was detected in the marrow cavities of the developing mandibular bone, in Meckel's cartilage, around the ducts of the salivary glands (arrows), and around the epithelial fold that separates the tongue from the lower jaw region (arrowhead). $\mathbf{c}$ In situ zymography of the same region as in $\mathbf{b}$, except that the slide was precoated with DQ-gelatin before adsorbing the tissue section, and no substrate was added to the gelatinase reaction buffer. Note that this technique produced a very similar fluorescence pattern as observed in b, although with higher background. This indicates that the fluorescent signal generated in $\mathbf{b}$ was not due to differential binding of DQgelatin to the section. $E$ eye, $F B$ forebrain, $M B$ mandibular bone, $M C$ Meckel's cartilage, $N C$ nasal cavity, $T B$ tooth buds, $T N$ tongue. Bars $500 \mu \mathrm{m}(\mathbf{a}) ; 200 \mu \mathrm{m}(\mathbf{b}, \mathbf{c})$

have gained special interest in studies on tumor invasion and metastasis (Clark et al. 2010; Nelson et al. 2000). However, they are also associated with a variety of biological processes such as bone remodeling (Martignetti et al. 2001), angiogenesis (Deryugina and Quigley 2006), immune response and inflammation (Merkle et al. 2010), and tissue repair (Zhang et al. 2011). Moreover, from genetic studies on both humans (Al Aqeel et al. 2000; Lombardi et al. 2008) and mice (Egeblad et al. 2007; Miettinen et al. 1999; Mosig et al. 2007; Robbins et al. 1999), there is strong evidence indicating that MMP-2 and -9 activity is important for various aspects of craniofacial development. In addition, there are reports that other MMPs are important for head morphogenesis. For example MMP-13 (collagenase-3), which besides fibrillar collagen also efficiently cleaves gelatin and other ECM components (Knauper et al. 1997), has been implicated in secondary palate formation (Blavier et al. 2001). Similarly, membrane-bound MMP-14 (MT1-MMP) has been shown to be involved in this process (Shi et al. 2008), presumably because it is required for activating pro-MMP-2 (Evans and Itoh 2007).

The biological function of MMPs, including gelatinases, is subjected to various levels of endogenous regulation: gene transcription, enzyme synthesis and secretion, proenzyme activation, and activity inhibition by endogenous tissue factors, such as $\alpha 2$-macroglobulins or tissue inhibitors of metalloproteinases (TIMPs) (Baker et al. 2002; Nelson et al. 2000). Techniques used for quantification and localization of mRNA or protein do not provide information about the functional activity of MMPs. Therefore, zymography techniques have been developed for the analysis of enzymatic activity of MMPs in biological samples. 
Zymography on gelatin-containing SDS-polyacrylamide gels is a well-established technique for the detection of enzymes with gelatinolytic activity in bulk biological samples (Frederiks and Mook 2004). Both the active and latent forms of each specific enzyme can be detected, identified according to their molecular weight, and quantified. This is important since apart from MMP-2 and MMP-9, several other proteinases can also cleave gelatin (Snoek-van Beurden and Von den Hoff 2005). However, because SDS disrupts the interactions between MMPs and inhibitors such as TIMPs, it is impossible to detect the net functional activity that is present in a sample (Ikeda et al. 2000; Woessner 1995). Moreover, SDS gel zymography does not allow to determine the tissue location and cellular origin of enzyme activity (Snoek-van Beurden and Von den Hoff 2005).

During the last years, techniques for the in situ detection of gelatinolytic activity on tissue sections have been developed. One example is the in situ film zymography, a low-cost technique that is relatively easy to perform but has limited sensitivity and reproducibility (Abiko et al. 1999; Ikeda et al. 2000; Mungall et al. 1998). Tissue sections are overlaid with a gelatin-based photographic emulsion, and after development a (usually) negative image results from its digestion over areas with gelatinolytic activity. However, tissue structures cannot be observed in detail since histology is obscured by the emulsion in undigested areas. In situ zymography (ISZ) using an overlay of fluorescent substrate is another option, but with similar limitations (Frederiks and Mook 2004; Galis et al. 1995; Yan and Blomme 2003).

A major advance occurred by introducing dye-quenched (DQ) substrates, such as DQ-gelatin, into ISZ (Oh et al. 1999). Since such substrates are excessively labeled with fluorescent dye, emitted photons are quenched by adjacent fluorophores. Digestion results in spatial separation of fluorophores and dequenching, causing an increase in fluorescence. Thus, areas with gelatinolytic activity are visualized as highly fluorescent sites on a less intense background. This method is more sensitive than other methods, and due to uncompromised histology provides more detailed information on the localization of gelatinolytic activity. Since its introduction, it has been applied repeatedly with encouraging results (Frederiks and Mook 2004; Porto et al. 2009; Wang and Tsirka 2005; Yan and Blomme 2003).

Several protocols have been reported regarding ISZ with DQ-gelatin substrates. Frederiks and Mook (2004) proposed to use an overlay of $1 \% \mathrm{w} / \mathrm{v}$ low gelling temperature agarose containing DQ-gelatin for the in situ detection of gelatinolytic activity in frozen unfixed sections. This protocol has been used to study craniofacial tissues (Sakakura et al. 2007; Sakuraba et al. 2006). However, the difficulty to produce an even gel layer may influence the reproducibility and sensitivity of the method. For gelatin ISZ combined with immunohistochemistry, Frederiks and Mook (2004) suggested to perform first the antibody labeling on acetonefixed sections and then to proceed with ISZ. However, the influence of acetone fixation on the sensitivity of the zymography was not commented. In an alternative approach, a solution of DQ-gelatin dissolved in incubation buffer (without agarose) was placed directly on the section (Clark et al. 2010; Nagel et al. 2004; Wang and Tsirka 2005). This opened the possibility to label with antibodies after completion of ISZ (Clark et al. 2010; Wang and Tsirka 2005). Based on the latter approach, we devised a simple, high resolution method for in situ detection of gelatinolytic activity in combination with subsequent immunofluorescence labeling on frozen sections of mouse embryo heads. We tested different protocols reported in the literature in order to optimize sensitivity. The method was validated by various types of control experiments with inhibitors, as well as by supplementary techniques such as SDS gel zymography. Frontal sections of the developing mouse head at embryonic days E14.5 and E15.5 showing the region of mandibular bone, Meckel's cartilage, and tongue were analyzed. Whereas gelatinolytic activity had been detected before in Meckel's cartilage and mandibular bone at a similar stage (Sakakura et al. 2007), our optimized ISZ/ immunofluorescence double-labeling technique allowed for the first time to colocalize activity with a subset of embryonic basement membranes underneath growing epithelia.

\section{Materials and methods}

Animals, embryonic tissue, and cryosectioning

C57BL/6 wild-type mouse embryos were obtained from J.-F. Spetz at the Friedrich-Miescher Institute for Biomedical Research (FMI) in Basel, Switzerland. After mating, appearance of a vaginal plug was taken as embryonic day 0.5 (E0.5). Pregnant females were killed at the desired stage (E14.5 or E15.5), embryos were removed from the uterus and decapitated. All procedures were approved by the Cantonal Veterinary Office of Basel, Switzerland. The embryo heads were washed in ice-cold PBS, soaked and embedded in Tissue Tek (O.C.T. compound; Sakura Finetek Europe B.V., Zoeterwoude, The Netherlands), and frozen on a metal block cooled to $-80^{\circ} \mathrm{C}$. Alternatively, heads were fixed in $4 \%$ paraformaldehyde in phosphate buffered saline (PBS; $150 \mathrm{mM} \mathrm{NaCl}, 20 \mathrm{mM}$ Na-phosphate, $\mathrm{pH}$ 7.4) overnight, washed briefly in PBS, soaked for $24 \mathrm{~h}$ in $30 \%$ sucrose in PBS, embedded in Tissue Tek, and frozen. All tissues were stored at $-80{ }^{\circ} \mathrm{C}$ before sectioning. Serial frontal sections (10-12 $\mu \mathrm{m}$ thick) of the embryo 
Table 1 Brief description of the protocols tested on unfixed cryostat sections of E14.5 wild-type mouse heads

$\begin{array}{lll}\text { Substrate } \quad \text { Application of substrate } & \begin{array}{l}\text { Incubation } \\ \text { period }\end{array}\end{array}$

A. ISZ protocols tested

1. $100 \mu \mathrm{g} / \mathrm{ml} \mathrm{DQ}-$ gelatin $+1 \%$ agarose

2. 50 or $100 \mu \mathrm{g} / \mathrm{ml}$ DQgelatin $+1 \%$ agarose

3. $50 \mu \mathrm{g} / \mathrm{ml}$ DQgelatin $+1 \%$ agarose

4. $50 \mu \mathrm{g} / \mathrm{ml} \mathrm{DQ}-$ gelatin

Application of the substrate over the sections using a glass cylinder and a piece of parafilm to obtain an even substrate layer, coverage with coverslips and incubation

As above + extra ISZ buffer over the substrate prior to coverage and incubation

Rinse and preincubation of slides with ISZ buffer for $30 \mathrm{~min} \quad 3 \mathrm{~h}$ and proceed as above

As in protocol 1

Application of the substrate on the sections and proceed as described in "Materials and methods"

Use of slides precoated with $20 \mu \mathrm{g} / \mathrm{ml}$ DQ-gelatin substrate and proceed as described in "Materials and methods"

5. 20 or $50 \mu \mathrm{g} / \mathrm{ml}$ DQ-gelatin

6. $20 \mu \mathrm{g} / \mathrm{ml} \mathrm{DQ}-$ gelatin
$6,24 \mathrm{~h}$

$0,3,34 \mathrm{~h}$

$24 \mathrm{~h}$

(1)

\section{h}

\author{
Non-specific signal, reduced \\ reproducibility, moderate \\ preservation of tissue structure \\ integrity \\ As in protocol $1+$ bad preservation of \\ tissue structure integrity
}

As in protocol 2

Specific signal, inhibition by EDTA \& Phen. Moderate preservation of tissue structure integrity

$0,1.5,3, \quad$ Specific signal, inhibition/no signal by $24 \mathrm{~h} \quad$ all inhibitors/controls tested, excellent preservation of tissue structures

Specific signal, good preservation of tissue structures, high background (inappropriate for high magnification)

\begin{tabular}{|c|c|c|}
\hline & Technique for ISZ + IF & Quality of the result \\
\hline \multicolumn{3}{|l|}{ B. ISZ + IF protocols tested } \\
\hline $\mathrm{IF}+20 \mu \mathrm{g} / \mathrm{ml}$ DQ-gelatin & $\begin{array}{l}\text { As described in "Materials and methods" } \\
\text { changing the sequence of methods applied and } \\
\text { without any fixation }\end{array}$ & $\begin{array}{l}\text { Good IF signal, partially specific but much } \\
\text { reduced ISZ signal, moderate preservation of } \\
\text { tissue structure integrity }\end{array}$ \\
\hline acetone $+\mathrm{IF}+20 \mu \mathrm{g} / \mathrm{ml}$ DQ-gelatin & $\begin{array}{l}\text { As described in "Materials and methods", while } \\
\text { changing the sequence of methods applied }\end{array}$ & $\begin{array}{l}\text { Good IF signal, partially specific but much } \\
\text { reduced ISZ signal, bad preservation of tissue } \\
\text { structure integrity }\end{array}$ \\
\hline $20 \mu \mathrm{g} / \mathrm{ml}$ DQ-gelatin + IF & $\begin{array}{l}\text { As described in "Materials and methods", } \\
\text { without any fixation }\end{array}$ & $\begin{array}{l}\text { Good IF signal, specific but moderate to good } \\
\text { ISZ signal, moderate preservation of tissue } \\
\text { structure integrity }\end{array}$ \\
\hline $20 \mu \mathrm{g} / \mathrm{ml}$ DQ-gelatin + acetone $+\mathrm{IF}$ & As described in "Materials and methods" & $\begin{array}{l}\text { Good IF signal, good ISZ signal, excellent } \\
\text { preservation of tissue structure integrity }\end{array}$ \\
\hline
\end{tabular}

$\overline{\text { A. Detection of gelatinolytic activity by in situ zymography (ISZ) alone; B. ISZ and immunofluorescence (IF) on the same section (double staining) }}$

heads were prepared on a Cryocut E cryomicrotome (Reichert-Jung, Leica Microsystems, Heerbrugg, Switzerland), dried at $37{ }^{\circ} \mathrm{C}$ for $1-5 \mathrm{~min}$, and stored at $-80{ }^{\circ} \mathrm{C}$ before further use.

\section{Histology}

For standard histology, cryosections prepared from formaldehyde-fixed tissue (see above) were stained with hematoxylin/eosin (H\&E). Slides were incubated in Meyer's hematoxylin solution (Merck, Zug, Switzerland) for $2 \mathrm{~min}$, immersed in $0.1 \% \mathrm{HCl}$ for $2 \mathrm{~s}$, washed with tap water for $5 \mathrm{~min}$, stained with $0.5 \%$ Eosin G/Y solution (Merck) containing $0.2 \%$ acetic acid for $3 \mathrm{~min}$, washed with tap water for $30 \mathrm{~s}$, dehydrated in an ethanol series followed by xylene, and embedded in Entellan (Merck).

In situ zymography

A brief description of the protocols tested for in situ zymography (ISZ) is provided in Table 1A, and for ISZ combined with immunofluorescence on the same section in Table 1B. Fluorescein-conjugated, dye-quenched gelatin from pig skin (DQ ${ }^{\mathrm{TM}}$-gelatin) was obtained from Molecular Probes (Invitrogen, Basel, Switzerland). A $1 \mathrm{mg} / \mathrm{ml}$ stock solution of DQ-gelatin was prepared in gelatinase reaction buffer $\left(150 \mathrm{mM} \mathrm{NaCl}, 5 \mathrm{mM} \mathrm{CaCl}_{2}, 0.2 \mathrm{mM} \mathrm{NaN}_{3}, 50 \mathrm{mM}\right.$ Tris- $\mathrm{HCl}, \mathrm{pH} 7.6)$ and stored at $4{ }^{\circ} \mathrm{C}$. Prior to storage and 
use, it is advisable to pass the stock solution of DQ-gelatin through a sterile syringe filter (cellulose acetate, $0.2 \mu \mathrm{m}$ pore size) in order to remove all fluorescent precipitates. In the standard procedure (Table 1A), the working solution for in situ zymography was made by directly diluting DQ-gelatin stock solution in reaction buffer to a final concentration of $20 \mu \mathrm{g} / \mathrm{ml}$. Unfixed cryosections were thawed, rounded with a wax pen, overlaid with $250 \mu \mathrm{l} \mathrm{DQ}$-gelatin working solution (for approximately half of the slide), and incubated at $37^{\circ} \mathrm{C}$ in a dark wet chamber. For the standard ISZ protocol proposed we concluded that $3 \mathrm{~h}$ of incubation is an ideal time for providing adequate signal while differentiating optimally between regions with higher or lower activity. After three washes with PBS, sections were either processed for immunofluorescence (see below), or mounted directly in $90 \%$ glycerol in PBS containing $10 \mathrm{mg} / \mathrm{ml}$ propyl 3,4,5trihydroxybenzoate (Merck, Darmstadt, Germany) as antifading agent. Sections could be stored at $4{ }^{\circ} \mathrm{C}$ for at least 2 weeks without losing significant information. However, it should be kept in mind that unless the sections are post-fixed (see below), the gelatinolytic reaction may continue during storage even at low temperature, leading to changes in the fluorescent signal.

In certain experiments, empty slides were precoated with $150 \mu \mathrm{l}$ DQ-gelatin $(20 \mu \mathrm{g} / \mathrm{ml})$, and the solution was allowed to dry for $10 \mathrm{~min}$. Afterwards, slides were washed with sterile $\mathrm{H}_{2} \mathrm{O}$ for $5 \mathrm{~s}$ and allowed to dry for $5 \mathrm{~min}$. These slides were then used to pick up sections prepared on the cryomicrotome. For ISZ, sections on DQ-gelatin-precoated slides were covered with $250 \mu$ l gelatinase reaction buffer alone and processed as described above.

For negative controls, the DQ-gelatin was either omitted from the gelatinase reaction buffer, or replaced by $20 \mu \mathrm{g} / \mathrm{ml}$ unlabeled pig skin gelatin (Merck). The effects of $4 \%$ paraformaldehyde fixation as well as of adding $2 \mathrm{mg} / \mathrm{ml}$ of unlabeled gelatin to the working DQ-gelatin solution were also tested. Additional experiments were performed to control for the specificity of the enzyme reaction. First, incubation was done both at 4 and $37{ }^{\circ} \mathrm{C}$ with three incubation time periods: 0 , 1.5 , and $3 \mathrm{~h}$. Second, either of the following metalloproteinase inhibitors was added to the DQ-gelatin working solution prior to incubation of the slides: $10 \mathrm{mM}$ ethylenediamine tetraacetic acid (EDTA; Merck; replacing $\mathrm{CaCl}_{2}$ in the reaction buffer); 0.2-3\% dimethyl sulfoxide (DMSO; Sigma); $1 \mathrm{mM}$ 1,10-phenanthroline (Phen; Sigma, Buchs, Switzerland); or $50 \mu \mathrm{M}$ (2R)-[(4-biphenylsulfonyl)amino]- $N$-hydroxy-3-phenylpropionamide (BiPS; MMP-2/MMP-9 inhibitor II; Calbiochem/Merck Chemicals, Nottingham, UK).

\section{Immunofluorescence staining}

In early trials to combine ISZ with antibody labeling, we followed a published protocol (Frederiks and Mook 2004) in which immunofluorescence staining was done first on acetone-fixed sections, before proceeding with ISZ. However, we observed that prior acetone fixation hampered the gelatinolytic reaction, thus reducing the sensitivity of the method (not shown). In the standard protocol (Table 1A), we therefore started with ISZ on unfixed cryosections, before fixing the zymography pattern and continuing with immunolabeling (Table 1B). Cold acetone proved to be an appropriate fixative with optimal performance for both techniques; cross-linking fixatives such as paraformaldehyde had to be avoided since they reduced ISZ-generated fluorescence and interfered with binding of certain antibodies (not shown). Immediately after processing for ISZ (see above), sections were fixed in cold acetone $\left(-20{ }^{\circ} \mathrm{C}\right)$ for $1 \mathrm{~min}$, then incubated with $3 \%$ bovine serum albumin in PBS (BSA/PBS) for $10 \mathrm{~min}$, and then with primary antibody diluted in BSA/PBS for 45 min at room temperature. To block endogenous mouse $\operatorname{IgG}$, sections to be stained with mouse monoclonal antibody (see below) were previously incubated with unlabeled goat-anti-mouse IgG (1:50; Cappel/MP Biomedicals, Santa Ana, CA) in BSA/ PBS for $1 \mathrm{~h}$. The following primary antibodies were used: rabbit anti-horse serum fibronectin (1:200; Wehrle and Chiquet 1990); rabbit anti-mouse EHS laminin (1:200; Paulsson et al. 1987); rat monoclonal antibody mTn12 against mouse tenascin-C (hybridoma supernatant 1:10; Aufderheide and Ekblom 1988); goat anti-mouse MMP-2 (1:20; R\&D Systems, Abingdon, UK); goat anti-mouse MMP-9 (1:20; R\&D Systems); mouse monoclonal antibody against human MMP-13 (crossreacts with mouse MMP-13; $10 \mu \mathrm{g} / \mathrm{ml}$; R\&D Systems); goat anti-human MT1-MMP/MMP14 (1:20; R\&D Systems). After three washes in BSA/PBS, sections were covered for $30 \mathrm{~min}$ with the respective secondary antibody (rhodamine-conjugated goat anti-rabbit or goat anti-rat IgG from Cappel/MP Biomedicals, Santa Ana, CA; Cy3-conjugated mouse antigoat IgG from Jackson ImmunoResearch/Milan Analytica, Rheinfelden, Switzerland; Alexa-Fluor 568 labeled goat anti-mouse IgG from Molecular Probes/Invitrogen, Basel, Switzerland) diluted 1:100 in BSA/PBS. After washing in DEPC-treated $\mathrm{H}_{2} \mathrm{O}$, slides were mounted in buffered glycerol with anti-fading agent (see above).

\section{Microscopy}

Slides were viewed with $10 \times$ and $40 \times$ fluorescence objectives on a Olympus BX-51 microscope equipped with epifluorescence optics, using mirror units U-MWIBA3 for fluorescein (DQ-gelatin) and U-MWIGA3 for rhodamine and Cy3 (secondary antibodies), respectively. Digital images were recorded using a ProgRes CT3 CMOS camera and ProgRes Capture Pro software (Jenoptik, Jena, Germany). For each objective, all slides from one experiment 
were photographed at exactly the same camera settings, and resulting images were processed identically.

\section{SDS gel zymography}

Zymography after SDS-polyacrylamide gel electrophoresis (SDS-PAGE) (Laemmli 1970) was performed as published (Trachslin et al. 1999). Briefly, $0.1 \%$ pig skin gelatin (Merck) was added to the polyacrylamide (10\%) solution before polymerization of the gel. E14.5 wild-type mouse embryo heads were extracted in SDS sample buffer (Laemmli 1970) (300 $\mu$ l per head) and $7 \mu$ extract was loaded on the gel per lane. In control experiments, culture medium conditioned by lipopolysaccharide-stimulated human macrophages (10 $\mu \mathrm{l}$ per lane) was loaded instead. After electrophoresis, the polyacrylamide gels were washed four times for 15 min with $2.5 \%$ Triton X-100, $10 \mathrm{mM}$ Tris- $\mathrm{HCl}, \mathrm{pH} 8.0$, and four times for $5 \mathrm{~min}$ in $50 \mathrm{mM}$ Tris- $\mathrm{HCl}, \mathrm{pH}$ 8.0. Gels were then incubated in gelatinase reaction buffer (see above) for $48 \mathrm{~h}$ at $37^{\circ} \mathrm{C}$, washed in distilled $\mathrm{H}_{2} \mathrm{O}$ for $10 \mathrm{~min}$, stained with Coomassie Blue for $1 \mathrm{~h}$, destained with $25 \%$ isopropanol/ $10 \%$ acetic acid in water for $30 \mathrm{~min}$, then destained with $10 \%$ isopropanol/10\% acetic acid in water for $3 \mathrm{~h}$ and photographed. To control for the specificity of the enzyme reaction, incubation was also performed by adding one of the above-mentioned metalloproteinase inhibitors to the incubation buffer in the same concentrations to those used for the ISZ experiments.

\section{Results}

In situ zymography with DQ-gelatin: optimization and controls

In a first series of experiments, we tested various protocols to optimize and validate in situ zymography with DQgelatin on unfixed frontal cryosections from a defined region of the E14.5 wild-type mouse head (Fig. 1a). We obtained the best results by diluting DQ-gelatin (final concentration $20 \mu \mathrm{g} / \mathrm{ml}$ ) directly in zymography buffer and then incubating unfixed cryosections with this working solution for $3 \mathrm{~h}$ at $37{ }^{\circ} \mathrm{C}$ (see "Materials and methods"). As reported previously (Sakakura et al. 2007), gelatinolytic activity was observed prominently in the developing mandibular bone and in Meckel's cartilage. Interestingly, on the same sections quite strong activity was also detected as sharp profiles surrounding distinct epithelial structures, such as the ducts of the salivary glands and the epithelial fold that separates the tongue from the lower jaw region (Fig. 1b).

Various controls were performed to confirm the specificity of the enzymatic reaction and hence of the observed fluorescent image. First, the pattern of activity remained unchanged when DQ-gelatin was not added directly to the zymography buffer, but when instead the slides were precoated with substrate before sections were adsorbed and incubated with buffer (Fig. 1c). This confirmed that the result obtained by directly adding DQ-gelatin to
Oh
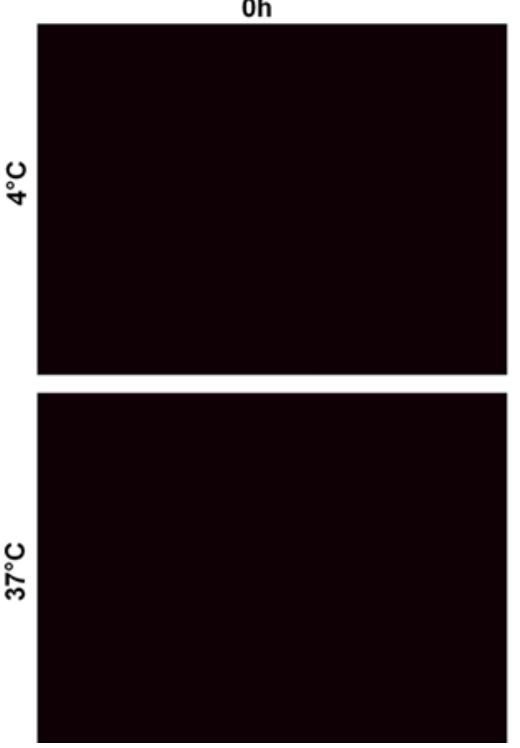

$1.5 \mathrm{~h}$
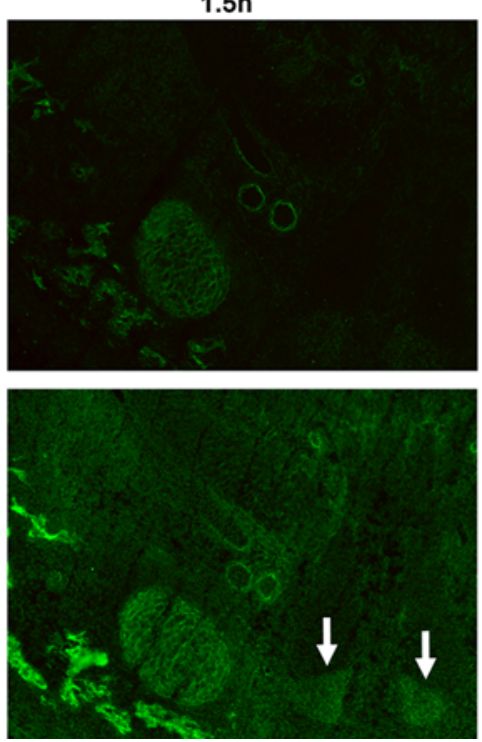

$3 \mathrm{~h}$
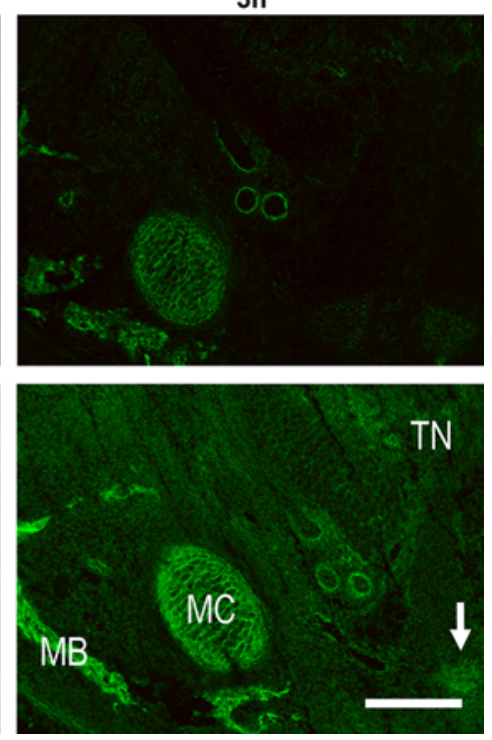

Fig. 2 Influence of temperature and incubation time on development of the fluorescent signal during DQ-gelatin in situ zymography. Unfixed frontal cryosections of a E14.5 wild-type mouse head were incubated with DQ-gelatin working solution (see "Materials and methods") at either $4{ }^{\circ} \mathrm{C}$ or $37^{\circ} \mathrm{C}$ for $0,1.5$, or $3 \mathrm{~h}$, respectively. The fluorescent signal increased with time and temperature, indicating that it was due to an enzymatic reaction. Note also that apart from the regions shown already in Fig. 1, gelatinolytic activity was detected in the myotendinous insertion of the main tongue muscle (arrows). $M B$ mandibular bone, $M C$ Meckel's cartilage, $T N$ tongue. Bar $200 \mu \mathrm{m}$ 

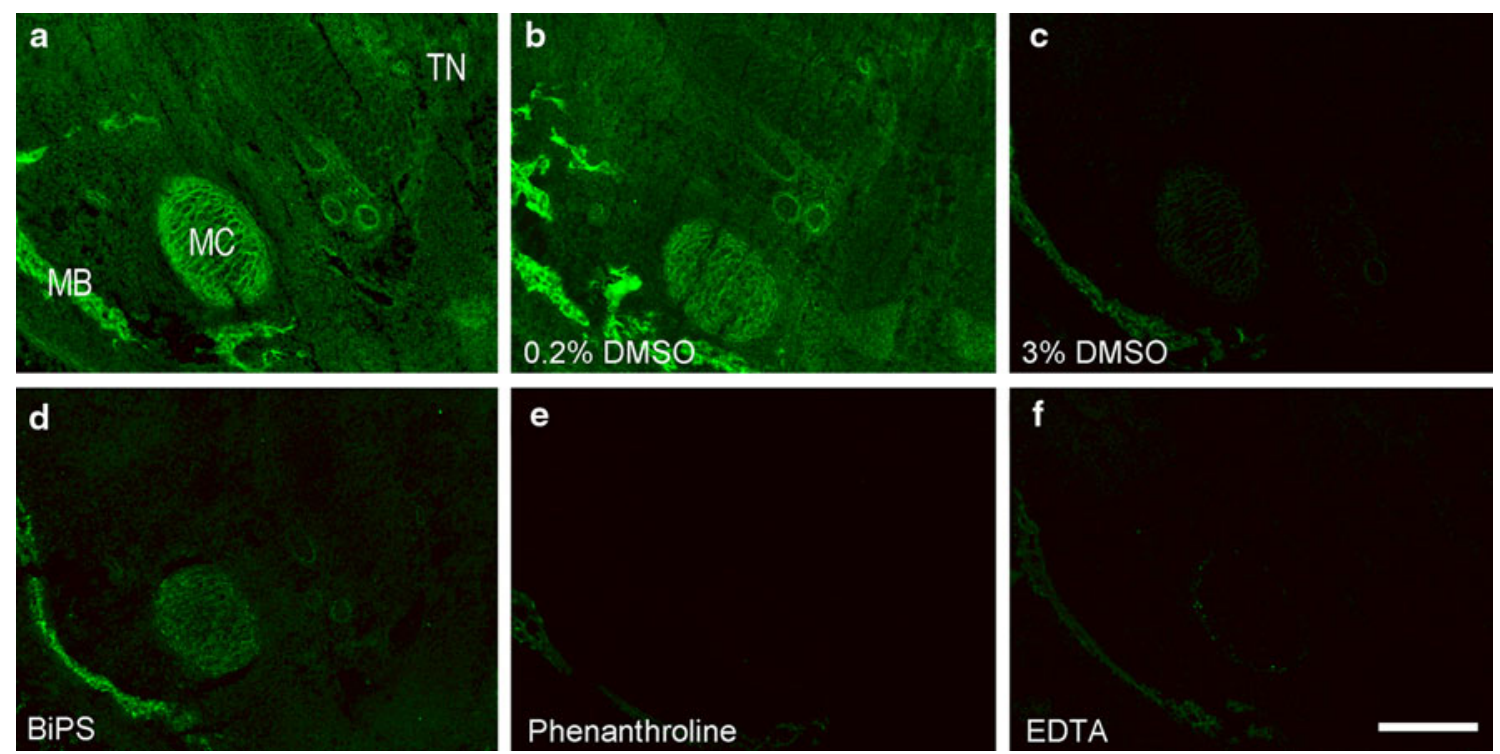

Fig. 3 Effect of MMP inhibition on development of fluorescent signal during DQ-gelatin in situ zymography. Unfixed frontal cryosections of a E14.5 wild-type mouse head were incubated with DQ-gelatin according to the standard procedure (see "Materials and methods"), without or with addition of inhibitors to the reaction buffer. a Control without inhibitor. b Inclusion of $0.2 \%$ DMSO (used as carrier for MMP-2/MMP-9 inhibitor) did not inhibit the

zymography buffer cannot be attributed to differential binding of the substrate to the section. However, we stopped pursuing the precoating method because it yielded a higher background fluorescence (Fig. 1c).

For a second control, the gelatinolytic reaction was shown to be time dependent, since increased fluorescence was observed with prolonged incubation time $(0,1: 30$, $3 \mathrm{~h})$. Incubation at decreased temperature $\left(4^{\circ} \mathrm{C}\right)$ showed a reduction of fluorescence increase with time compared to incubation at $37{ }^{\circ} \mathrm{C}$ (Fig. 2). Both of these findings indicate that the final result is due to an enzymatic reaction.

Furthermore, ISZ of serial sections showed that the fluorescent signal was reduced when adding excess unlabeled gelatin to the DQ-substrate solution (Supplementary Fig. S1a, b). Incubation with zymography buffer alone (Fig. S1c) did not give any signal. ISZ on paraformaldehyde-fixed sections also resulted in essentially no fluorescence (Fig. S1d).

The addition of various types of inhibitors to the zymography buffer resulted in partial or complete inhibition of fluorescence generated by DQ-gelatin cleavage. Comparison of Fig. 3a (control) with Fig. 3b shows that inclusion of $0.2 \%$ DMSO, which was used as carrier for MMP-2/MMP-9 inhibitor (see below), did not inhibit the gelatinolytic reaction. In contrast, $3 \%$ DMSO strongly suppressed the gelatinolytic reaction (Fig. 3c), as has been published before (Xu et al. 2004). BiPS, a specific MMP-2/ MMP-9 inhibitor $(50 \mu \mathrm{M})$, partially attenuated the reaction gelatinolytic reaction. c In contrast, $3 \%$ DMSO significantly suppressed the gelatinolytic reaction. d Addition of a specific MMP-2/MMP-9 inhibitor (BiPS; $50 \mu \mathrm{M}$ ), partially attenuated the reaction. e General MMP inhibitors 1,10-phenanthroline (1 mM) and f EDTA $(10 \mathrm{mM})$ strongly suppressed the gelatinolytic activity. $M B$

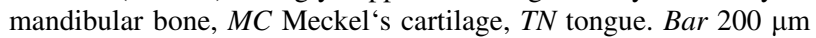

in situ (Fig. 3d). On the other hand, $1 \mathrm{mM}$ phenanthroline (Fig. 3e), a potent $\mathrm{Zn}^{2+}$ complexing agent and MMP inhibitor, or $10 \mathrm{mM}$ EDTA (Fig. 3f), a general divalent cation chelator and metalloproteinase antagonist, almost completely inhibited the gelatinolytic activity.

MMP-2 and MMP-9 detected in mouse embryo heads by SDS-gel zymography

To identify the major proteases responsible for gelatinolytic activity in the developing mouse embryo head, we subjected E14.5 craniofacial tissue extracts to gelatin zymography on SDS-polyacrylamide gels (Fig. 4). Expectedly, in these extracts we could identify MMP-2 and MMP-9 from their typical molecular weight on SDS gels (72 and $92 \mathrm{kDa}$, respectively, for the unprocessed latent forms). Both latent and smaller active forms were present for the two enzymes. MMP-2 was the dominant gelatinase, while MMP-9 was much less abundant (Fig. 4a). Incubation of gels with zymography buffer containing various inhibitors showed a similar pattern of inhibition to that observed in zymography in situ. More specifically, $0.2 \%$ DMSO did not inhibit the gelatinolytic reaction, while $3 \%$ DMSO suppressed it. MMP-2/MMP-9 inhibitor BiPS $(50 \mu \mathrm{M})$, phenanthroline $(1 \mathrm{mM})$ or EDTA $(10 \mathrm{mM})$ appeared to completely abolish the gelatinolytic activity of both MMP-2 and MMP-9 (Fig. 4a). However, since MMP-9 activity is only weakly visible in E14.5 extracts, we wanted 

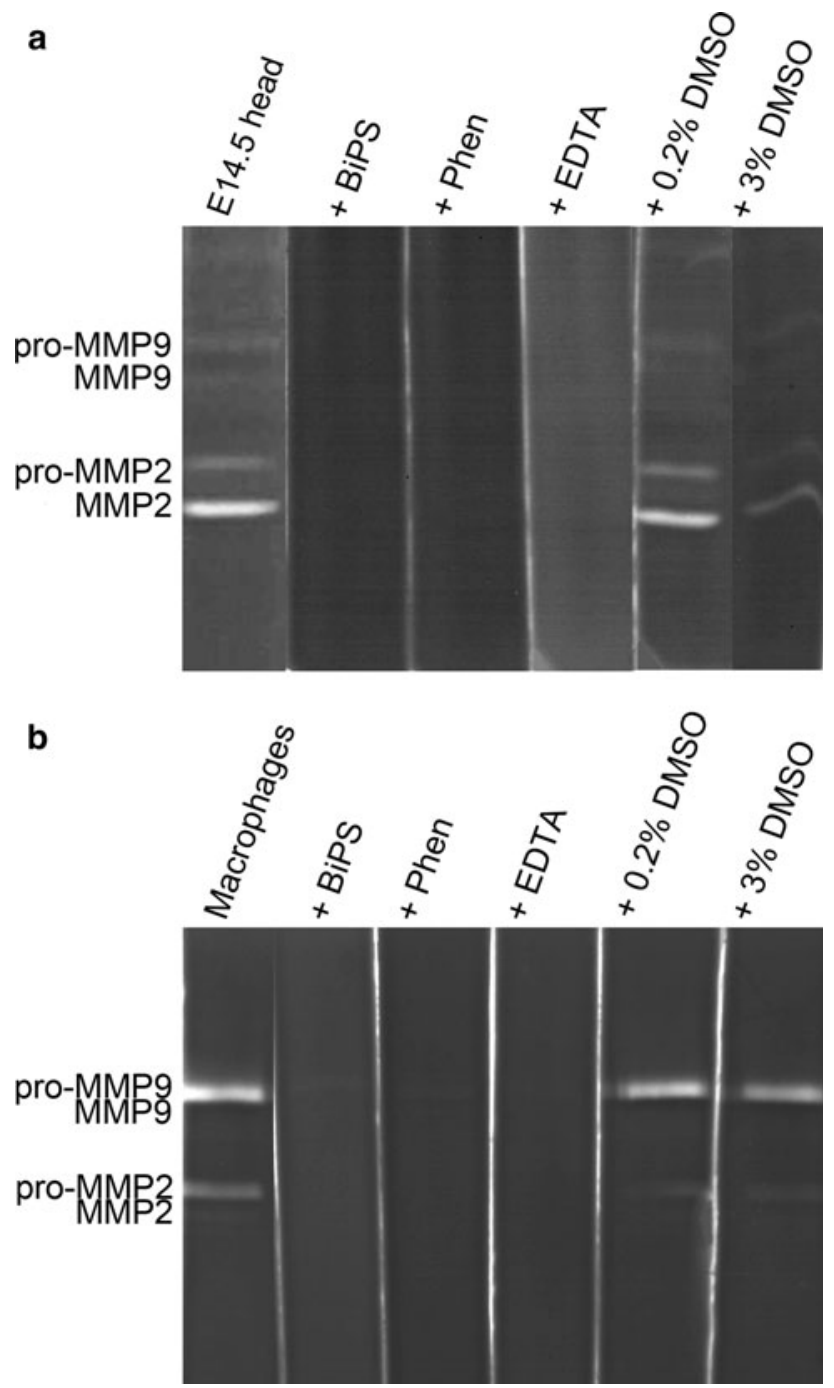

Fig. 4 Detection of MMP-2 and MMP-9 activity in extracts of E14.5 mouse embryo heads by SDS-gel zymography, and effect of inhibitors. a E14.5 wild-type mouse head extracts were run on $10 \%$ polyacrylamide-SDS gels containing $0.1 \%$ gelatin. Gels were washed, developed for zymography in the absence or presence of inhibitors, and stained with Coomassie. Pro-MMP-9 (92 kDa), MMP$9(80 \mathrm{kDa})$, pro-MMP-2 (72 kDa), and MMP-2 (68 kDa) were identified by their relative molecular weight on the gel. The control (lane at left) revealed a significant amount of MMP-2 and less MMP9 activity in the developing mouse head. $1 \mathrm{mM}$ phenanthroline, $10 \mathrm{mM}$ EDTA, and $50 \mu \mathrm{M}$ specific MMP-2/MMP-9 inhibitor (BiPS) all suppressed gelatinolytic activity. 0.2 \% DMSO did not significantly inhibit MMP-2 activity while $3 \%$ DMSO did. b Same as a, except that macrophage conditioned medium (Macrophages) rich in MMP-9 was run on an SDS-gel for zymography. Results were identical to a except for $3 \%$ DMSO, which barely inhibited MMP-9

to confirm that the inhibitors used here indeed act on this enzyme as well. Thus, we repeated SDS gel zymography using macrophage cell culture supernatants where MMP-9 is more abundant, and this led to similar findings apart from weak or no inhibition of MMP-9 by $3 \%$ DMSO (Fig. 4b).
Colocalization of gelatinolytic activity with immunolabeling for MMPs

A major technical aim of this study was to combine, on the same slide, immunolabeling with ISZ without compromising the sensitivity of the latter method. Since ISZ with DQ-gelatin is most sensitive when performed on unfixed tissue sections (Clark et al. 2010), we developed a doublelabeling technique where zymography is done first, immediately followed by brief fixation with cold acetone and immunofluorescence labeling (see "Materials and methods").

Using this technique, we first aimed at investigating the relationship between MMP protein distribution and gelatinolytic activity (Fig. 5). This is an important issue because the proenzymes need to be processed for activation; thus the distributions of latent and active gelatinases might differ. Using specific antibody, we found that MMP-2 protein has an almost ubiquitous distribution in the E14.5 mouse embryo head, although highest expression is found in the developing bone marrow cavity of the mandibular bone and in the perichondrium of Meckel's cartilage (Fig. 5b). Thus, whereas MMP-2 immunostaining showed perfect overlap with gelatinolytic activity in bone cavities, latent MMP-2 appeared to be enriched around Meckel's cartilage where enzyme activity was lower than in the cartilage proper. MMP-9 protein has a more restricted expression, but is also highly expressed in developing bone marrow where it overlaps with the zymography pattern (Fig. 5d). MMP-9 immunoreactivity was evident in the perichondrium of Meckel's cartilage together with MMP-2, but was also detected in the cartilage itself, and in smaller amounts near other regions that presented gelatinolytic activity, such as around the ducts of the salivary gland and the epithelial fold separating the tongue from the lower jaw region. MMP-9 was also highly expressed and colocalized with activity at the myotendinous insertion of the tongue skeletal muscle (Fig. 5d). Among other MMPs, collagenase 3 (MMP-13) is known to possess significant gelatinolytic activity in vitro (Knauper et al. 1997). Like for the classical gelatinases, MMP-13 immunoreactivity was very strong in the developing mandible, and prominent in the perichondrium (but not the interior) of Meckel's cartilage. MMP-13 was weakly but ubiquitously detectable in the mesenchyme, with some enrichment at the base of the tongue (Fig. 5f). We also tested an antibody to MMP-14/MT1-MMP. This membrane-bound enzyme is known to activate other MMPs, particularly MMP-2, and itself possesses gelatinolytic activity (Evans and Itoh 2007). In addition to strong expression again in bone cavities, MT1-MMP had a similar distribution as MMP-9, with the exception of Meckel's cartilage where it was 

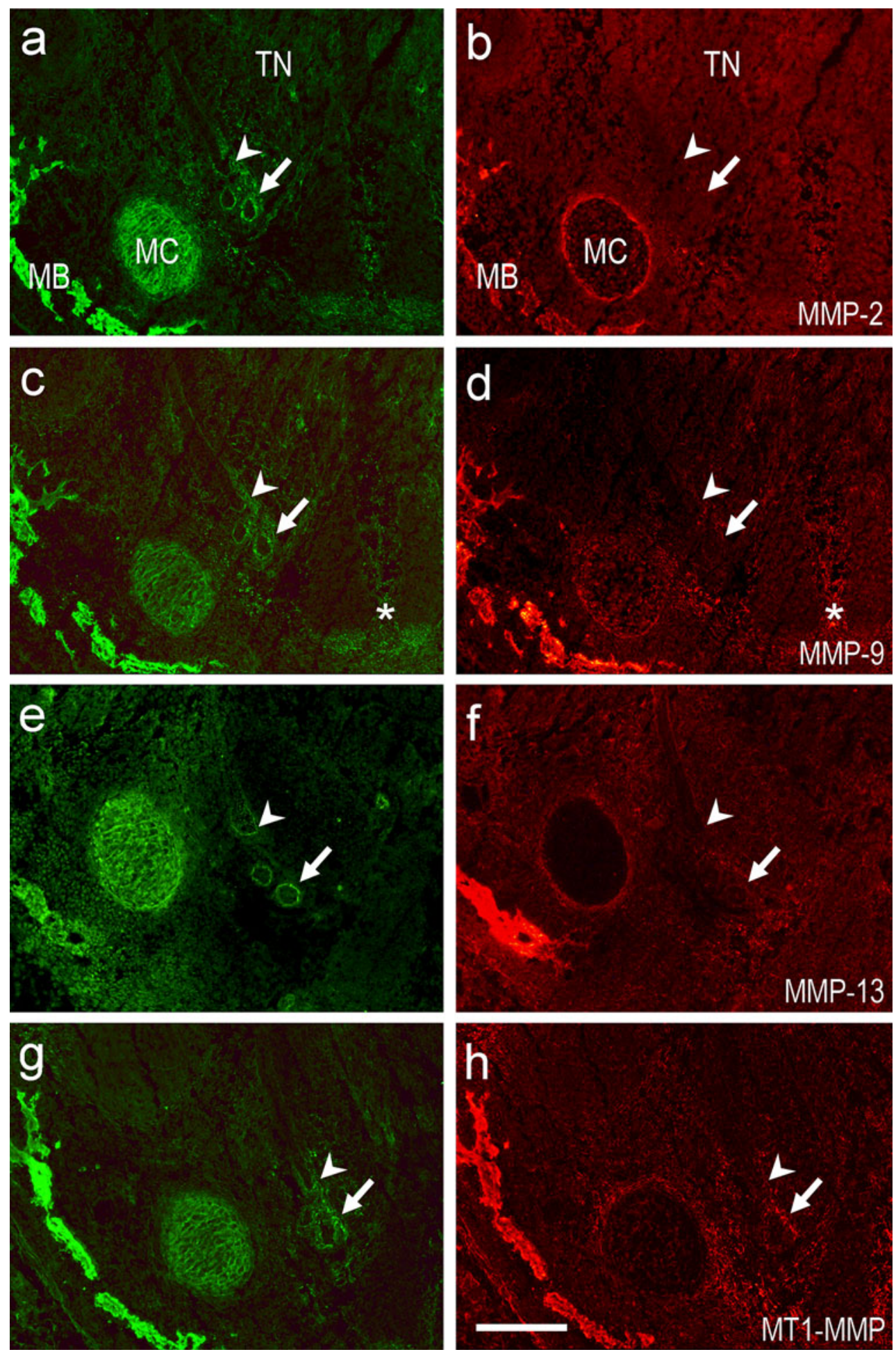

Fig. 5 Double labeling for gelatinolytic activity and MMPs in the craniofacial region of the mouse embryo. Frontal cryosections of a E14.5 wild-type mouse head were subjected to DQ-gelatin zymography, followed by immunofluorescence labeling for MMPs on the same section. In situ zymography and immunofluorescence labeling for MMP-2 (a, b), MMP-9 (c, d), MMP-13/collagenase-3 (e, f), and MT1-MMP/MMP-14 (g, h), respectively. Note extensive colocalization

of all four enzymes with strong gelatinolytic activity in the developing bone marrow cavities of the mandibles. The epithelial fold between the tongue and the lower jaw (arrowheads) and the salivary gland ducts (arrows), as well as the myotendinous insertion of the main tongue muscle (asterisks) are indicated. For more details, see "Results". $M B$ mandibular bone, $M C$ Meckel's cartilage, TN tongue. Bar $200 \mu \mathrm{m}$ 
(like MMP-2) enriched in the perichondrium rather than the cartilage proper (Fig. 5h). In summary, all four enzymes showed perfect codistribution with gelatinolytic activity in mandibular bone cavities, and partial overlap in other regions as described in more detail below.

Gelatinolytic activity in basement membranes of the mouse embryo head

In addition, we employed ISZ followed by immunohistochemistry to associate gelatinolytic activity in situ with specific extracellular matrix components and structures. Double staining for enzymatic reaction and ECM proteins on the same section revealed that tenascin-C was not colocalized with gelatinolytic activity except partially in developing mandibles (Fig. 6c, f). On the other hand, strong fibronectin staining was found together with prominent gelatinolysis in many regions, such as Meckel's cartilage, mandibles and salivary ducts (Fig. 6a, d). However, the overlap was not complete and differential staining was observed. For example, the basement membrane region of all larger blood vessels was intensely stained by anti-fibronectin. Of these, however, the major lingual artery was also brightly fluorescent after in situ zymography, whereas the periphery of other vessels exhibited little or no gelatinolytic activity (Fig. 6a, d). Laminin-111 immunostaining colocalized with gelatinolytic activity around the ducts of the salivary gland (Fig. 6b, e). Since laminin-111 is an integral component of embryonic basement membranes, this finding demonstrates that active MMPs must be closely associated with these structures in certain anatomical regions. Most interestingly, gelatinolytic activity was also found in the laminin-positive basement membrane of the oral epithelium, however, almost exclusively around the fold that separates the tongue from the lower jaw region, but barely in adjacent regions (Fig. 6b, e). Gelatinolytic activity codistributed perfectly with laminin immunostaining at the bottom of the epithelial fold, but faded out more cranially in the basement membrane (Fig. 7). This finding prompted us to re-examine more closely the distribution of gelatinolytic activity and MMP proteins in this specific region at a slightly later stage (E15.5; Fig. 8). Results were very similar for E14.5 and E15.5 apart from a moderate increase in both MMP activity (Fig. 8a, d, g, j) and expression (Fig. 8b, e, h, k) at the later stage. Antibody to MMP-2 profusely stained the entire area, with some enrichment in the basement membrane exhibiting gelatinolytic activity (Fig. 8a-c). Punctate MMP-9 immunolabeling was observed in the mesenchyme surrounding the epithelial fold as well as on the luminal surface; some overlap with enzyme activity was visible mainly in mesenchyme in close proximity to the basement
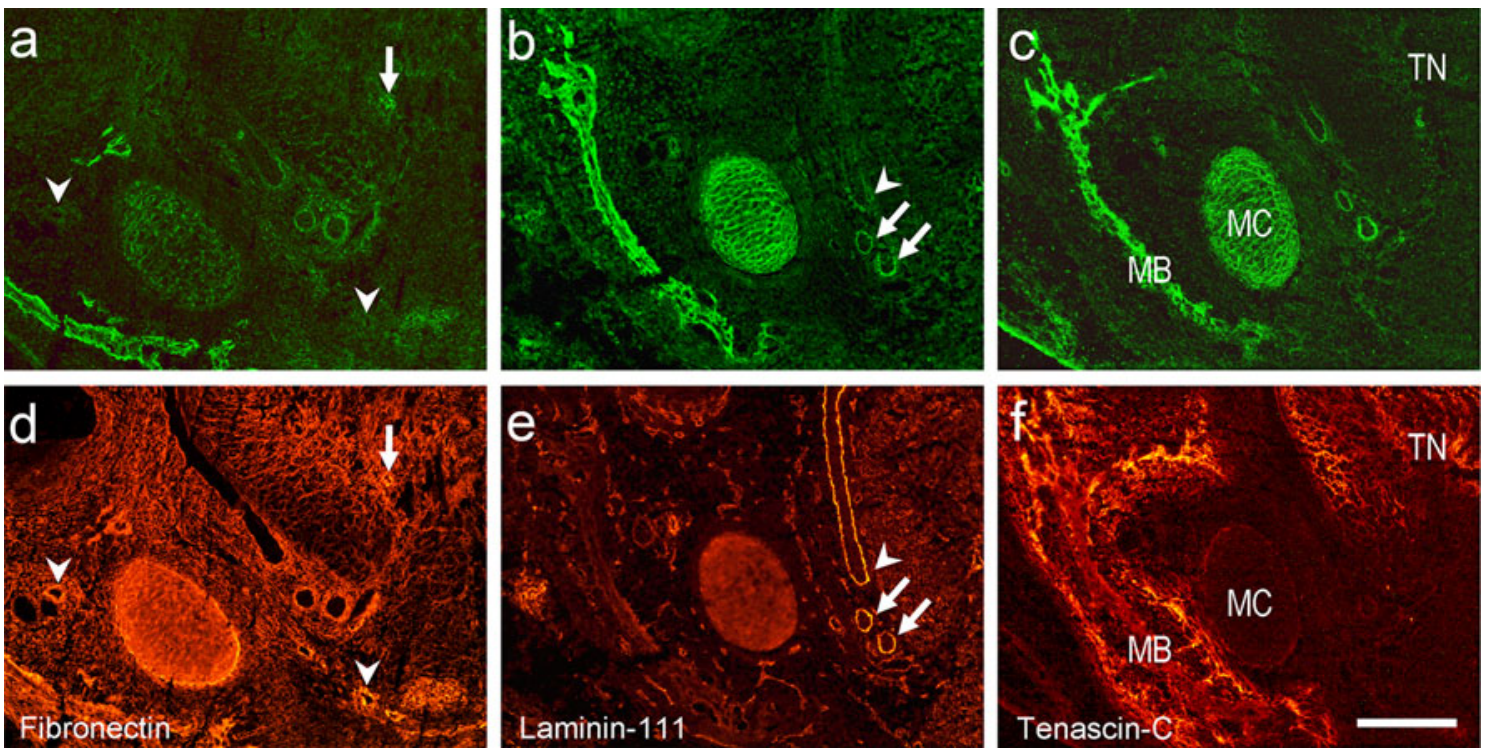

Fig. 6 Double labeling for gelatinolytic activity and extracellular matrix proteins in the craniofacial region of the mouse embryo. Frontal cryosections of a E14.5 wild-type mouse head were subjected to DQ-gelatin zymography, followed by immunofluorescence labeling for extracellular matrix proteins on the same section. a In situ zymography and d immunofluorescence labeling for fibronectin, respectively, revealed colocalization in Meckel's cartilage, mandibles, and salivary ducts. Note that certain larger blood vessels exhibited both intense fibronectin staining and gelatinolytic activity (arrows), whereas others were fibronectin-positive only (arrowheads). b In situ zymography and $\mathbf{e}$ immunofluorescence labeling for laminin, respectively, showed colocalization of gelatinolytic activity with basement membranes of the ducts of the salivary gland (arrows) and the epithelial fold that separates the tongue from the lower jaw region (arrowheads). c In situ zymography and $\mathbf{f}$ immunofluorescence labeling for tenascin-C, respectively, revealed little codistribution. $M B$ mandibular bone, $M C$ Meckel's cartilage, $T N$ tongue. Bar $200 \mu \mathrm{m}$ 

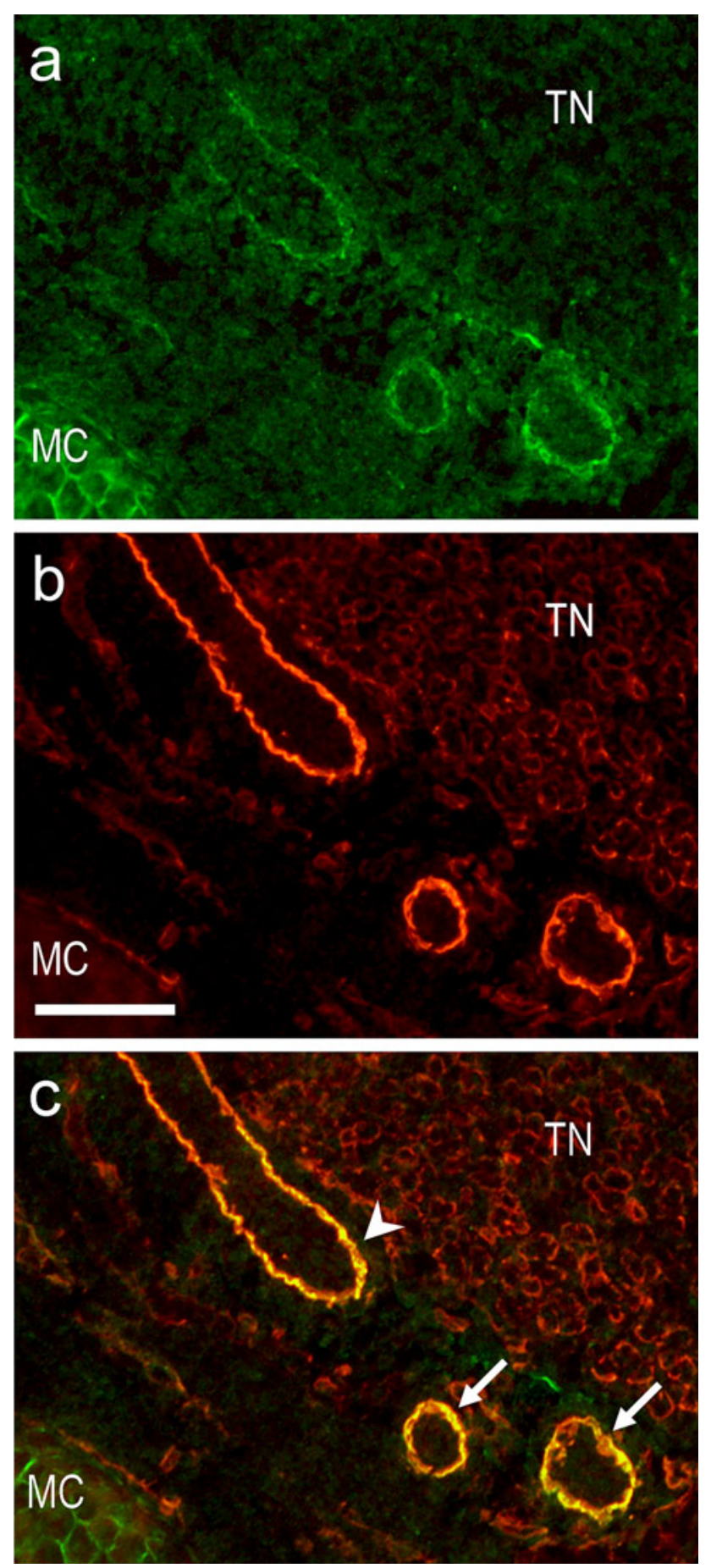

Fig. 7 Colocalization of gelatinolytic activity with specific basement membranes. Double-labeling a by in situ zymography and b by immunofluorescence staining for laminin of a frontal cryosection of a E14.5 wild-type mouse head; $\mathbf{c}$ is the merged image. The close-up image shows precise colocalization of gelatinolysis with epithelial basement membranes of the ducts of the salivary gland (arrows) and the epithelial fold separating the tongue from the lower jaw region (arrowhead). However, note that laminin-positive basement membranes of tongue $(T N)$ muscle fibers are negative for gelatinolytic activity. $M C$ Meckel's cartilage, $T N$ tongue. Bar $50 \mu \mathrm{m}$ membrane (Fig. 8d-f). MMP13 was associated with fibrillar matrix around the epithelial fold, and was found to overlap with gelatinolytic activity in the basement membrane as evidenced by a thin yellow line in the merged image (Fig. 8g-i). A quite precise codistribution between activity and immunostaining was found for MT1-MMP in the mesenchyme in punctate and fibrillar structures, and at the periphery of the positive basement membrane area (Fig. 8j-1). Thus, MMP-2 and MMP-13 exhibit the clearest overlap with gelatinolysis in the basement membrane of the lingual fold, but the other two enzymes might contribute to activity at this specific site as well.

\section{Discussion}

The importance of MMP-mediated extracellular matrix remodeling for skeletal development is documented by genetic studies. In humans, for example, inactivating mutations in the Mmp2 gene cause Torg syndrome, which is characterized by facial abnormalities and severe deformations of the limbs (Zankl et al. 2007). Mice deficient for Mmp2 (Mosig et al. 2007) (Egeblad et al. 2007), Mmp9 (Vu et al. 1998), Mmpl3 (Stickens et al. 2004) and Mmpl4 (MT1-MMP; Holmbeck et al. 1999) have various defects in skeletal and craniofacial structures. Gelatinases and other MMP enzymes are prominently expressed during craniofacial development in the mouse embryo, as shown by immunolabeling (Chin and Werb 1997; Iamaroon et al. 1996). Two papers so far investigated actual MMP activity, rather than protein distribution, in the developing mammalian head by ISZ. An early study used in situ film zymography for the detection of gelatinolytic activity in the developing craniofacial tissues of the embryonic day 18 rat (Abiko et al. 1999). After overnight exposure, a strong signal was observed in eyes, tongue, Meckel's cartilage, mandibles, and salivary glands, and a weaker signal in association with oral and nasal epithelia. However due to the inherent disadvantages of the film overlay technique (see "Introduction"), the poor resolution of the images did not allow to assign gelatinolytic activity to specific cells or extracellular structures. A more recent paper focused on the development and resorption of Meckel's cartilage by ISZ with a DQ-gelatin/agarose overlay; immunocytochemistry for MMPs was performed in parallel on consecutive sections (Sakakura et al. 2007). In the present study, we investigated the in situ pattern of gelatinolytic activity in a confined but informative region of the E14.5 embryo mouse head using DQ-gelatin as substrate. We confirmed earlier results, but in addition were able to identify gelatinolytic activity in specific minute structures such as certain basement membranes. Through a series of experiments 

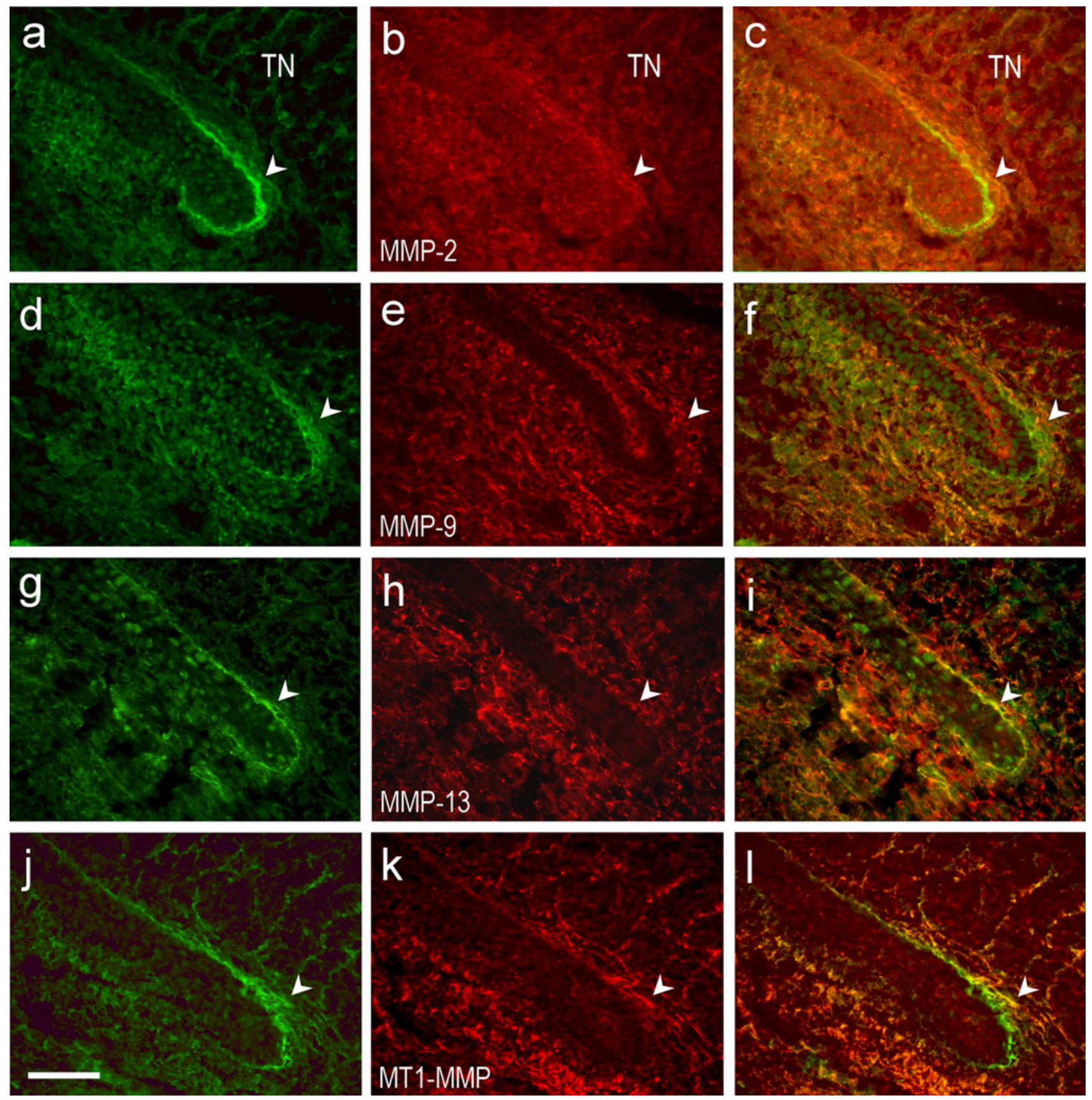

Fig. 8 Partial overlap of MMP immunostaining with gelatinolytic activity in the basement membrane of the lingual fold. Frontal cryosections of a E15.5 wild-type mouse head were subjected to DQgelatin zymography, followed by immunofluorescence labeling for MMPs on the same section. In situ zymography (left row) and immunofluorescence labeling (middle row) for MMP-2 (a-c), MMP-9

we developed a convenient and effective method for detecting gelatinolytic activity on unfixed cryostat sections, which can be combined with subsequent immunofluorescence staining to localize the responsible enzymes and their potential ECM substrates on the same section. To achieve the highest possible sensitivity, zymography was (d-f), MMP-13 (g-i) and MT1-MMP (j-l), respectively. Merged images are shown at right $(\mathbf{c}, \mathbf{f}, \mathbf{i}, \mathbf{l})$. Note partial colocalization (yellow color in merged images) primarily of MMP-2 (c) and MMP13 (i) with the basement membrane of the epithelial fold (lingual fold; arrowheads) that separates the tongue (TN) from the lower jaw region. For more details, see "Results". Bar $50 \mu \mathrm{m}$

performed on unfixed cryosections first, followed by fixation in ice-cold acetone (which best preserves the ISZ pattern as well as antigenicity), and then sections were labeled with antibodies. In preliminary ISZ experiments, we immobilized the DQ-gelatin substrate by coating it on slides, before adsorbing the cryosections. However, based 
on published procedures (Clark et al. 2010; Nagel et al. 2004; Wang and Tsirka 2005) we later added DQ-gelatin substrate directly to the enzyme buffer, which gave identical results but reduced background fluorescence. Of course, with this simplified method the question arises as to how the DQ-gelatin stays fixed in place after cleavage by MMPs. It has been suggested that its fluorescent cleavage products remain bound to the gelatinases (Clark et al. 2010). As an alternative (or an additional) possibility, we presume that DQ-gelatin in solution binds to fibronectin, which is present in high amounts and almost ubiquitously in embryonic tissue (Chiquet et al. 1981), and which has high affinity for gelatin (Ehrismann et al. 1981). This of course raises the possibility that the fluorescence patterns obtained by in situ zymography with soluble DQ-gelatin (Clark et al. 2010; Nagel et al. 2004; Wang and Tsirka 2005; our results) are confounded by the underlying fibronectin distribution in the tissue. Two of our observations indicate that this is not the case. First, as already mentioned, in situ zymography with DQ-gelatin immobilized on slides yielded the same fluorescence patterns as seen with soluble substrate. Second, although there was considerable overlap between fibronectin staining and observed gelatinolytic activity, notable differences were evident between the two patterns (see Fig. 6). Thus, our findings indicate that also with the simplified ISZ method using soluble substrate, the fluorescence pattern faithfully reflects sites of gelatinolytic activity.

We used inhibitors of varying specificity in order to define the source of gelatinolytic activity detected with ISZ on our sections. EDTA, a general metalloproteinase inhibitor, as well as phenanthroline, a more specific MMP inhibitor, completely abolished the reaction both in ISZ and SDS gel zymography. $3 \%$ DMSO, which has been shown to inhibit MMP-2 activity by disrupting interactions between its collagen-binding domain and the substrate (Xu et al. 2004), significantly attenuated the reaction in situ, and almost completely inhibited MMP-2 on the SDS-gel zymogram. On the other hand, MMP-9 activity was only slightly reduced by $3 \%$ DMSO on the gel. This finding, combined with a certain degree of remaining activity in situ particularly in bone, suggested that there is some redundancy between the two major gelatinases in vivo, as has been also shown by knockout gene studies (BruniCardoso et al. 2010; Lambert et al. 2003). The more specific MMP-2/MMP-9 inhibitor BiPS completely inhibited the enzymatic reaction of the two major gelatinases in gel zymography, but only partially suppressed gelatinolytic activity in situ. Taken together, these results suggest that part of the activity detected in situ originates also from other MMPs, such as MT1-MMP, which has been shown to degrade gelatin as well (Overall 2002). By immunofluorescence, we therefore examined the localization of MMP-2, MMP-9, MMP-13, and MT1-MMP proteins, and compared it to gelatinolytic activity on the same sections. The first two MMPs not only constitute the major proteinases for the degradation of denatured fibrillar collagens, but also cleave basement membrane and other minor collagens, namely collagen types IV, V, and VII (Hibbs et al. 1987; Odaka et al. 2005; Overall 2002). Of the mammalian collagenases, MMP-13 (collagenase-3) has been associated with craniofacial development (Blavier et al. 2001) and is known to cleave gelatin and other ECM components in addition to fibrillar collagens (Knauper et al. 1997). MT1MMP is a major activator of pro-MMP-2, whereby the synergistic action of the two metalloproteinases leads to increased proteolytic activity (Kudo et al. 2007; Nishida et al. 2008). Thus, these four molecules are likely to be responsible for most of the gelatinolytic activity that was detected through ISZ. As expected, our results confirmed the presence of either MMP-2, MMP-9, MMP-13, or MT1MMP in and near several regions that presented gelatinolytic activity. All four MMP proteins overlapped precisely with very strong gelatinolytic activity in the bone marrow cavities of the developing mandibles. Both MMP-2 and -9 colocalized with activity in Meckel's cartilage proper, but staining for MMP-2 protein was even stronger in the perichondrium where little activity was observed. This is a clear example of divergence between enzyme distribution and activity, either because MMP-2 in perichondrium occurs mostly as proenzyme, or because the active form is inhibited by endogenous antagonists e.g. TIMPs.

The distribution of three major ECM proteins, namely fibronectin, laminin, and tenascin-C, was also tested by immunofluorescence in combination with ISZ, because the first two (but not tenascin-C) have been shown to be substrates for MMP-2, MMP-9, and MT1-MMP, whereas tenascin-C is cleaved only by MMP-13 (Butler and Overall 2009; Koshikawa et al. 2000; Overall 2002; Zamilpa et al. 2010). Indeed, our findings showed colocalization of gelatinolytic activity with fibronectin and laminin in several regions, but not with tenascin-C except in mandibles. As mentioned, the overlap between fibronectin staining and enzyme activity was quite extensive. Interesting differences were observed especially for major blood vessels: the walls of all vessels were brightly stained by anti-fibronectin, but only a subset also exhibited strong gelatinolytic activity. We do not know yet what characterizes these two types of vessels, and the significance of the finding awaits further studies. Perhaps even more interesting was the detection of gelatinolytic activity in the basement membrane of the oral epithelium, however, restricted to the site where it folds back onto itself at the base of the tongue and the lower jaw region. Co-staining with specific antibodies showed that MMP-2 and MMP-13 were clearly overlapping with gelatinolytic activity in the basement membrane 
at this site, whereas MMP-9 and MT1-MMP were more peripherally associated. One might speculate that increased extracellular matrix turnover is required at this site for maintaining the epithelial fold (and hence the opening of the oral cavity) during growth of the tongue and the mandibles. The present findings, which are based on a simple but sensitive high resolution method to colocalize gelatinolytic activity with specific extracellular matrix structures in the embryo, form the basis to test such a hypothesis.

Acknowledgments We thank Susan Blumer for valuable suggestions and excellent technical support, Sabrina Ruggiero for initial help with SDS-gel zymography, Jean-François Spetz for providing us with mouse embryos, and Neha Gadhari for critical reading of the manuscript.

\section{References}

Abiko Y, Kutsuzawa M, Kowashi Y, Kaku T, Tachikawa T (1999) In situ detection of gelatinolytic activity in developing craniofacial tissues. Anat Embryol (Berl) 200:283-287

Aiken A, Khokha R (2010) Unraveling metalloproteinase function in skeletal biology and disease using genetically altered mice. Biochim Biophys Acta 1803:121-132

Al Aqeel A, Al Sewairi W, Edress B, Gorlin RJ, Desnick RJ, Martignetti JA (2000) Inherited multicentric osteolysis with arthritis: a variant resembling Torg syndrome in a Saudi family. Am J Med Genet 93:11-18

Aufderheide E, Ekblom P (1988) Tenascin during gut development: appearance in the mesenchyme, shift in molecular forms, and dependence on epithelial-mesenchymal interactions. J Cell Biol 107:2341-2349

Baker AH, Edwards DR, Murphy G (2002) Metalloproteinase inhibitors: biological actions and therapeutic opportunities. J Cell Sci 115:3719-3727

Blavier L, Lazaryev A, Groffen J, Heisterkamp N, DeClerck YA, Kaartinen V (2001) TGF-beta3-induced palatogenesis requires matrix metalloproteinases. Mol Biol Cell 12:1457-1466

Bruni-Cardoso A, Lynch CC, Rosa-Ribeiro R, Matrisian LM, Carvalho HF (2010) MMP-2 contributes to the development of the mouse ventral prostate by impacting epithelial growth and morphogenesis. Dev Dyn 239:2386-2392

Butler GS, Overall CM (2009) Updated biological roles for matrix metalloproteinases and new "intracellular" substrates revealed by degradomics. Biochemistry 48:10830-10845

Chin JR, Werb Z (1997) Matrix metalloproteinases regulate morphogenesis, migration and remodeling of epithelium, tongue skeletal muscle and cartilage in the mandibular arch. Development 124:1519-1530

Chiquet M, Eppenberger HM, Turner DC (1981) Muscle morphogenesis: evidence for an organizing function of exogenous fibronectin. Dev Biol 88:220-235

Clark IM, Young DA, Rowan AD (2010) Matrix metalloproteinase protocols. Humana Press, New York

Deryugina EI, Quigley JP (2006) Matrix metalloproteinases and tumor metastasis. Cancer Metastasis Rev 25:9-34

Egeblad M, Shen HC, Behonick DJ, Wilmes L, Eichten A, Korets LV, Kheradmand F, Werb Z, Coussens LM (2007) Type I collagen is a genetic modifier of matrix metalloproteinase 2 in murine skeletal development. Dev Dyn 236:1683-1693
Ehrismann R, Chiquet M, Turner DC (1981) Mode of action of fibronectin in promoting chicken myoblast attachment. $\mathrm{Mr}=60,000$ gelatin-binding fragment binds native fibronectin. J Biol Chem 256:4056-4062

Evans RD, Itoh Y (2007) Analyses of MT1-MMP activity in cells. Methods Mol Med 135:239-249

Frederiks WM, Mook OR (2004) Metabolic mapping of proteinase activity with emphasis on in situ zymography of gelatinases: review and protocols. J Histochem Cytochem 52:711-722

Galis ZS, Sukhova GK, Libby P (1995) Microscopic localization of active proteases by in situ zymography: detection of matrix metalloproteinase activity in vascular tissue. FASEB J 9:974980

Hibbs MS, Hoidal JR, Kang AH (1987) Expression of a metalloproteinase that degrades native type $\mathrm{V}$ collagen and denatured collagens by cultured human alveolar macrophages. J Clin Invest 80:1644-1650

Holmbeck K, Bianco P, Caterina J, Yamada S, Kromer M, Kuznetsov SA, Mankani M, Robey PG, Poole AR, Pidoux I, Ward JM, Birkedal-Hansen H (1999) MT1-MMP-deficient mice develop dwarfism, osteopenia, arthritis, and connective tissue disease due to inadequate collagen turnover. Cell 99:81-92

Iamaroon A, Wallon UM, Overall CM, Diewert VM (1996) Expression of $72-\mathrm{kDa}$ gelatinase (matrix metalloproteinase-2) in the developing mouse craniofacial complex. Arch Oral Biol 41:1109-1119

Ikeda M, Maekawa R, Tanaka H, Matsumoto M, Takeda Y, Tamura Y, Nemori R, Yoshioka T (2000) Inhibition of gelatinolytic activity in tumor tissues by synthetic matrix metalloproteinase inhibitor: application of film in situ zymography. Clin Cancer Res 6:3290-3296

Knauper V, Cowell S, Smith B, Lopez-Otin C, O'Shea M, Morris H, Zardi L, Murphy G (1997) The role of the C-terminal domain of human collagenase-3 (MMP-13) in the activation of procollagenase-3, substrate specificity, and tissue inhibitor of metalloproteinase interaction. J Biol Chem 272:7608-7616

Koshikawa N, Giannelli G, Cirulli V, Miyazaki K, Quaranta V (2000) Role of cell surface metalloprotease MT1-MMP in epithelial cell migration over laminin-5. J Cell Biol 148:615-624

Kudo T, Takino T, Miyamori H, Thompson EW, Sato H (2007) Substrate choice of membrane-type 1 matrix metalloproteinase is dictated by tissue inhibitor of metalloproteinase-2 levels. Cancer Sci 98:563-568

Laemmli UK (1970) Cleavage of structural proteins during the assembly of the head of bacteriophage T4. Nature 227:680-685

Lambert V, Wielockx B, Munaut C, Galopin C, Jost M, Itoh T, Werb Z, Baker A, Libert C, Krell HW, Foidart JM, Noel A, Rakic JM (2003) MMP-2 and MMP-9 synergize in promoting choroidal neovascularization. FASEB J 17:2290-2292

Lombardi F, Fasciglione GF, D'Apice MR, Vielle A, D'Adamo M, Sbraccia P, Marini S, Borgiani P, Coletta M, Novelli G (2008) Increased release and activity of matrix metalloproteinase- 9 in patients with mandibuloacral dysplasia type $\mathrm{A}$, a rare premature ageing syndrome. Clin Genet 74:374-383

Martignetti JA, Aqeel AA, Sewairi WA, Boumah CE, Kambouris M, Mayouf SA, Sheth KV, Eid WA, Dowling O, Harris J, Glucksman MJ, Bahabri S, Meyer BF, Desnick RJ (2001) Mutation of the matrix metalloproteinase 2 gene (MMP2) causes a multicentric osteolysis and arthritis syndrome. Nat Genet 28:261-265

Merkle M, Ribeiro A, Sauter M, Ladurner R, Mussack T, Sitter T, Wornle M (2010) Effect of activation of viral receptors on the gelatinases MMP-2 and MMP-9 in human mesothelial cells. Matrix Biol 29:202-208

Miettinen PJ, Chin JR, Shum L, Slavkin HC, Shuler CF, Derynck R, Werb Z (1999) Epidermal growth factor receptor function is 
necessary for normal craniofacial development and palate closure. Nat Genet 22:69-73

Mosig RA, Dowling O, DiFeo A, Ramirez MC, Parker IC, Abe E, Diouri J, Aqeel AA, Wylie JD, Oblander SA, Madri J, Bianco P, Apte SS, Zaidi M, Doty SB, Majeska RJ, Schaffler MB, Martignetti JA (2007) Loss of MMP-2 disrupts skeletal and craniofacial development and results in decreased bone mineralization, joint erosion and defects in osteoblast and osteoclast growth. Hum Mol Genet 16:1113-1123

Mott JD, Werb Z (2004) Regulation of matrix biology by matrix metalloproteinases. Curr Opin Cell Biol 16:558-564

Mungall BA, Pollitt CC, Collins R (1998) Localisation of gelatinase activity in epidermal hoof lamellae by in situ zymography. Histochem Cell Biol 110:535-540

Nagel H, Laskawi R, Wahlers A, Hemmerlein B (2004) Expression of matrix metalloproteinases MMP-2, MMP-9 and their tissue inhibitors TIMP-1, -2 , and -3 in benign and malignant tumours of the salivary gland. Histopathology 44:222-231

Nelson AR, Fingleton B, Rothenberg ML, Matrisian LM (2000) Matrix metalloproteinases: biologic activity and clinical implications. J Clin Oncol 18:1135-1149

Nishida Y, Miyamori H, Thompson EW, Takino T, Endo Y, Sato H (2008) Activation of matrix metalloproteinase-2 (MMP-2) by membrane type 1 matrix metalloproteinase through an artificial receptor for ProMMP-2 generates active MMP-2. Cancer Res 68:9096-9104

Odaka C, Tanioka M, Itoh T (2005) Matrix metalloproteinase-9 in macrophages induces thymic neovascularization following thymocyte apoptosis. J Immunol 174:846-853

Oh LY, Larsen PH, Krekoski CA, Edwards DR, Donovan F, Werb Z, Yong VW (1999) Matrix metalloproteinase-9/gelatinase B is required for process outgrowth by oligodendrocytes. J Neurosci 19:8464-8475

Overall CM (2002) Molecular determinants of metalloproteinase substrate specificity: matrix metalloproteinase substrate binding domains, modules, and exosites. Mol Biotechnol 22:51-86

Parks WC, Wilson CL, Lopez-Boado YS (2004) Matrix metalloproteinases as modulators of inflammation and innate immunity. Nat Rev Immunol 4:617-629

Paulsson M, Aumailley M, Deutzmann R, Timpl R, Beck K, Engel J (1987) Laminin-nidogen complex. Extraction with chelating agents and structural characterization. Eur J Biochem 166:11-19

Porto IM, Rocha LB, Rossi MA, Gerlach RF (2009) In situ zymography and immunolabeling in fixed and decalcified craniofacial tissues. J Histochem Cytochem 57:615-622

Robbins JR, McGuire PG, Wehrle-Haller B, Rogers SL (1999) Diminished matrix metalloproteinase 2 (MMP-2) in ectomesenchyme-derived tissues of the Patch mutant mouse: regulation of MMP-2 by PDGF and effects on mesenchymal cell migration. Dev Biol 212:255-263

Sakakura Y, Hosokawa Y, Tsuruga E, Irie K, Yajima T (2007) In situ localization of gelatinolytic activity during development and resorption of Meckel's cartilage in mice. Eur J Oral Sci $115: 212-223$
Sakuraba I, Hatakeyama J, Hatakeyama Y, Takahashi I, Mayanagi H, Sasano Y (2006) The MMP activity in developing rat molar roots and incisors demonstrated by in situ zymography. J Mol Histol 37:87-93

Shi J, Son MY, Yamada S, Szabova L, Kahan S, Chrysovergis K, Wolf L, Surmak A, Holmbeck K (2008) Membrane-type MMPs enable extracellular matrix permissiveness and mesenchymal cell proliferation during embryogenesis. Dev Biol 313:196-209

Snoek-van Beurden PA, Von den Hoff JW (2005) Zymographic techniques for the analysis of matrix metalloproteinases and their inhibitors. Biotechniques 38:73-83

Stickens D, Behonick DJ, Ortega N, Heyer B, Hartenstein B, Yu Y, Fosang AJ, Schorpp-Kistner M, Angel P, Werb Z (2004) Altered endochondral bone development in matrix metalloproteinase 13-deficient mice. Development 131:5883-5895

Trachslin J, Koch M, Chiquet M (1999) Rapid and reversible regulation of collagen XII expression by changes in tensile stress. Exp Cell Res 247:320-328

Visse R, Nagase H (2003) Matrix metalloproteinases and tissue inhibitors of metalloproteinases: structure, function, and biochemistry. Circ Res 92:827-839

Vu TH, Shipley JM, Bergers G, Berger JE, Helms JA, Hanahan D, Shapiro SD, Senior RM, Werb Z (1998) MMP-9/gelatinase B is a key regulator of growth plate angiogenesis and apoptosis of hypertrophic chondrocytes. Cell 93:411-422

Wang J, Tsirka SE (2005) Neuroprotection by inhibition of matrix metalloproteinases in a mouse model of intracerebral haemorrhage. Brain 128:1622-1633

Wehrle B, Chiquet M (1990) Tenascin is accumulated along developing peripheral nerves and allows neurite outgrowth in vitro. Development 110:401-415

Woessner JF Jr (1995) Quantification of matrix metalloproteinases in tissue samples. Methods Enzymol 248:510-528

Xu X, Wang Y, Lauer-Fields JL, Fields GB, Steffensen B (2004) Contributions of the MMP-2 collagen binding domain to gelatin cleavage. Substrate binding via the collagen binding domain is required for hydrolysis of gelatin but not short peptides. Matrix Biol 23:171-181

Yan SJ, Blomme EA (2003) In situ zymography: a molecular pathology technique to localize endogenous protease activity in tissue sections. Vet Pathol 40:227-236

Zamilpa R, Lopez EF, Chiao YA, Dai Q, Escobar GP, Hakala K, Weintraub ST, Lindsey ML (2010) Proteomic analysis identifies in vivo candidate matrix metalloproteinase- 9 substrates in the left ventricle post-myocardial infarction. Proteomics 10:2214-2223

Zankl A, Pachman L, Poznanski A, Bonafe L, Wang F, Shusterman Y, Fishman DA, Superti-Furga A (2007) Torg syndrome is caused by inactivating mutations in MMP2 and is allelic to NAO and Winchester syndrome. J Bone Miner Res 22:329-333

Zhang HQ, Chang M, Hansen CN, Basso DM, Noble-Haeusslein LJ (2011) Role of matrix metalloproteinases and therapeutic benefits of their inhibition in spinal cord injury. Neurotherapeutics 8:206-220 